\title{
Rol vital de Enfermería, para la salud del todo el mundo
}

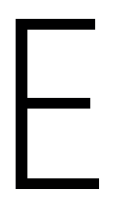

I año 2020, denominado por la Organización Mundial de la Salud (OMS), año de la Enfermera y la Partera, se ve afectado por COVID-19, virus con una patogenicidad devastadora en población vulnerable, que registra al día de hoy en el mundo 1,033,833 casos confirmados con 54, 378 muertes, en México 1510 contagios y 50 personas fallecidas ${ }^{(1)}$, lo que inyecta histeria colectiva, por la alta difusión de noticias sobre la pandemia y profunda reflexión que lleva a pensar en la salud, como el mayor bien del ser humano, así como en el papel crucial de los sistemas de salud del mundo ante la pandemia.

En este panorama el empoderamiento de la Enfermería es inminente, el mundo voltea a ver al personal sanitario y agradece el trabajo de enfermeras y enfermeros quienes se mantienen en la línea de lucha contra el virus, donde una alta proporción se infectan con COVID-19 (2), dicha realidad indica la profunda necesidad de proteger al personal de enfermería y otros trabajadores de la salud, como prioridad número uno en el mundo, ya que asumen valientemente su compromiso profesional y asisten a los nosocomios, con la intención de cuidar al que lo necesite, así como, intensificar las estrategias de prevención como el lavado de manos, trabajo a distancia y mantener distanciamiento social, lo anterior con el propósito de disminuir la trasmisión de la infección y reducir la presión sobre los sistemas de salud (3).

Se reconoce que los profesionales de enfermería quienes están en el corazón de la mayoría de los equipos sanitarios, desempeñan un papel crucial en la promoción de la salud, así como en la prevención y el tratamiento de enfermedades, no sólo del COVID-19, sino de aquellas más antiguas como Sarampión, Tuberculosis, Tosferina, Diabetes e Hipertensión y VIH, entre otras, y al ser los profesionales sanitarios más cercanos a la comunidad, desarrollan nuevos modelos de cuidados comunitarios y sostienen los esfuerzos realizados a escala local para promover la salud y prevenir la enfermedad, tal como lo señala la campaña Nursing Now.

¡Las enfermeras y enfermeros, también son seres humanos!, no son superhéroes, ni ángeles, sin embargo, se preparan con conocimientos científicos, habilidades prácticas y actitudes específicas, que permiten actuar en situaciones adversas y asumir con responsabilidad riesgos asociados al cuidado del ser humano, el llamado a los gobiernos es garantizar equipo de seguridad y protección adecuado, que se encuentre accesible y disponible para que enfermeras y enfermeros del mundo, ejerzan su trabajo en las condiciones idóneas y que no enfermen o mueran.

Por lo anterior, cuidar a los que cuidan, procurar un sistema inmune fortalecido, así como, bienestar psicológico de enfermeras y enfermeros y todos los miembros del equipo de salud, son cruciales en estos momentos, por lo cual, se insta a no sobre exponerse a noticias devastadoras y leer información precisa y legitima de fuentes oficiales como la OMS, además, de dar a conocer historias positivas y esperanzadoras de personas que han experimentado COVID-19.

Finalmente, se reitera el compromiso de enfermeras y enfermeros, como profesionales de la salud, para actuar y fortalecer cada uno de los campos de acción de enfermería, tanto asistencial, docente, gestión e investigación, realizando acciones preventivas y de información dando primordial enfoque a lo establecido por la OMS, ya que todos estamos aprendiendo de esta nueva enfermedad, lo que contribuirá al cambio de paradigmas en el cuidado de la salud humana en todo el mundo.

\section{Dra. María Olga Quintana-Zavala (]) \\ Doctora en Ciencias de Enfermería \\ Jefa del Departamento de Enfermería \\ Universidad de Sonora \\ olga.quintana@unison.mx}




\section{REFERENCIAS BIBLIOGRÁFICAS}

1. Coronavirus: ¿ayuda realmente a prevenir el contagio de covid-19 el quitarse toda la ropa al entrar a la casa y lavar todos los productos de la compra? [en línea]. América Latina: BBC News Mundo;2020. [Acceso el 02 de abril de 2020]. Disponible en: https://www.bbc.com/mundo/noticias-52115044

2. High proportion of healthcare workers with COVID-19 in Italy is a stark warning to the world: protecting nurses and their colleagues must be the number one priority [en línea]. Geneva: Internacional Council of Nursing (ICN); 2020. [Acceso el 30 de marzo de 2020]. Disponible en: https://www.icn.ch/sites/default/files/inline-files/PR_09_COVID-19\%20-\%20ltaly. pdf?fbclid=IwAR0N6PjHjY_2BPawSL5dBVbrQohKMtrWS5AEw5BVGd5pEfvTA6eo71DhQes

3. Coronavirus: ¿qué es "aplanar la curva" y por qué es tan importante para "retrasar y contener" la propagación del covid-19? [en línea]. América Latina: BBC News Mundo; 2020. [Acceso el 30 de marzo de 2020]. Disponible en: https:// www.bbc.com/mundo/noticias-51835806

Copyright $\odot 2020$ SANUS

Artículo de acceso abierto distribuido

bajo Licencia Creative Commons

\section{(c) (i) $\odot$}

\section{Cómo citar este artículo}

Quintana-Zavala MO. Rol vital de Enfermería, para la salud del todo el mundo. SANUS. 2020; (13):1-2.[Acceso_ _ _ _ ] ] Disponible en:__ 